\title{
The Efficacy of LUCAS in Cardiac Arrest
}

\author{
Alves A.I. ${ }^{1}$, Freitas C. ${ }^{2}$, Viveiros A. ${ }^{3}$, Ribeiro L. ${ }^{4}$, Gomes R. ${ }^{5}$, Pereira J. ${ }^{6}$, Veríssimo M. ${ }^{7}$, Fernandes O. ${ }^{8}$ \\ 1. MSc of in Food Consumption Science, MSc and Specialist in Medical-Surgical Nursing, DSc in Nursing, functions in the Intensive Care Unit of Hospital Dr. Nélio \\ Mendonça, Funchal, Madeira, Portugal. \\ 2. Specialist in Medical-Surgical Nursing, DSc in Nursing, Accessor of the Health Secretary of Madeira Island, functions in the Intensive Care Unit of Hospital Dr. Nélio \\ Mendonça and in Pré-hospitalar Emergency, Funchal, Madeira, Portugal. \\ 3. MSc DSc in Management in Nursing, Specialist in Medical-Surgical Nursing and in Intensive Care and Resuscitation, Chief of the Intensive Care Unit of Hospital Dr. \\ Nélio Mendonça, Funchal, Madeira, Portugal. \\ 4. Specialist in Medical-Surgical Nursing, DSc in Nursing, Nurse Coordinator of the Civil Protection Emergency Service, functions in the Intensive Care Unit of Hospital \\ Dr. Nélio Mendonça, Funchal, Madeira, Portugal. \\ 5. DSc in Nursing, functions in the Intensive Care Unit of Hospital Dr. Nélio Mendonça, Funchal, Madeira, Portugal \\ 6. Specialist in Nursing Medical-Surgical Nursing, DSc in Nursing, functions in Civil Protection Emergency Service and in the Intensive Care Unit of Hospital Dr. Nélio \\ Mendonça, Funchal, Madeira, Portugal. \\ 7. Specialist in Medical-Surgical Nursing, DSc in Nursing, functions in the Intensive Care Unit of Hospital Dr. Nélio Mendonça, Funchal, Madeira, Portugal. \\ 8. MSc and Specialist in Nursing Medical-Surgical Nursing, DSc in Nursing, functions in Civil Protection Emergency Service and in the Intensive Care Unit of Hospital \\ Dr. Nélio Mendonça, Funchal, Madeira, Portugal.
}

Corresponding author: Alves AI, e-mail: anaigalves@gmail.com

DOI: 10.29322/IJSRP.10.12.2020.p10822

http://dx.doi.org/10.29322/IJSRP.10.12.2020.p10822

\begin{abstract}
Introduction: Chest compression is the basic technique of cardiopulmonary resuscitation (CPR) in patients with cardiac arrest. The quality and early performance of CPR is critical to improve the prognosis and chances of restoring spontaneous blood flow. Today we have manual compressions and mechanical chest compression devices. Objective: The aim of this study is to clarify the importance of the LUCAS system (The Lund University Cardiac Arrest System) in CPR. Material and methods: A systematic review of the literature by mobilizing the descriptors "Cardiac Arrest", "Lucas Efficacy" and "nursing", using the methodological head. Ten conceivable databases were selected, between 2010-2020, and seven articles were included for analysis. Results and discussion: The results of the studies are different, as four of the studies indicate that LUCAS is fully effective, particularly in fatigue and transport, but two of them do not recognise its full effectiveness. One of the studies mentions that the fact that compression by the automatic device is effective does not necessarily reflect a better result. The vast majority of the studies recognise the need for further studies to make more convincing decisions. Conclusion: Mechanical chest compression devices can improve patient outcome if used appropriately in the event of cardiac arrest. The hemodynamic performance of the LUCAS compression-decompression system is, according to some results, better than manual CPR. However, the quality of the current evidence is not sufficient. Randomised studies are needed to evaluate the effect of mechanical chest compression devices on survival inside or outside the hospital.
\end{abstract}

Keywords: Cardiac Arrest, Lucas Efficacy and Nursing.

\section{INTRODUCTION}

ardiac arrest is an abrupt drop in heart activity that reduces the effective pumping of blood (Neumar et al., 2010). In the Clast 50 years, research has steadily improved cardiopulmonary resuscitation (CPR), but much remains to be done as survival rates remain low. The effectiveness of CPR depends on many factors, the most important being the speed and quality of the resuscitation procedure. All optimal parameters of such a procedure, such as time of execution, thoracic compression rate and thoracic compression rate, are given in the guidelines of American Heart Association (AHA) (Kleinman et al., 2015). Outside the hospital, cardiac arrest is the main cause of death and morbility (Nishiyama et al., 2014). A key factor that improves survival is high quality CPR (Stiell et al., 2012; Idris et al., 2015). The quality of CPR in 
ambulatory cardiac arrest is often suboptimal (Wik et al., 2005). Fatigue and the need to perform multiple tasks during cardiac arrest limit the quality of CPR. Cardiac arrest has a bleak prognosis, as usually only 5\% of patients are discharged alive and without neurological problems after an out-of-hospital cardiac arrest (Aufderheide, et al., 2011).

Mechanical chest compression devices provide compressions of standard depth and frequency over long periods of time without loss of quality and spare professionals from performing chest compressions manually, allowing them to focus on other aspects of patient care (Couper et al., 2015). The LUCAS device is a mechanical system for compression and decompression of the thorax that allows automated and continuous closed compression of the thorax without unduly restricting other invasive procedures (Agostini et al., 2008; Smekal et al., 2009; Wagner et al., 2010). Automated CPR devices have been developed to address some of the problems that reduce the effectiveness of manual CPR. The first of these problems, probably the most important, is the fatigue experienced by rescuers during CPR. In fact, the human thorax has a thick cushion that dissipates some of the energy applied during massage, so the rescuer must provide energy continuously (Wik et al., 2005; Idris et al., 2015). Over time, fatigue sets in and reduces the effectiveness of the massage (Riley et al., 2011; Perkins et al., 2012; Brooks et al., 2014). As a result, rescuers must change frequently, which interrupts the massage and further reduces the effectiveness of resuscitation (Hewitt et al., 2006).

However, since there is no evidence that automatic devices improve the outcome of CPR, AHA does not advocate their routine use. Nevertheless, such devices are a viable alternative when high-quality manual compression is challenging or dangerous for the provider (Nishiyama et al., 2014).

In this article, the different results of other articles will be analysed to verify the actual effectiveness of automatic CPR devices, in this case LUCAS.

\section{MATERIALS AND METHODS}

A systematic review of the literature is one of the research methods used in the practice of evidence-based research, and its purpose is to collect and summarize research findings on a particular topic in a systematic and orderly manner, thereby contributing to knowledge about the topic (Mendes et al., 2008; Benefield, 2003). The method used was based on the strategy PICO (acronym for patient, intervention, comparison and "outcomes"). In this way, it maximizes the inclusion of relevant information in different databases, focusing on the research object and avoiding unnecessary searches (Santos, Pimenta e Nobre, 2007).

In strict compliance with all the steps required for the application of this method, a protocol was developed between May and September 2020 to identify studies of interest for this work, consisting of searches in the search engines: Ebsco and BONline, and in the following databases: CINAHL Plus, PubMed/ MEDLINE, LILACS, Scielo, Web of Science, ScienceDirect and Repository of Scientific Open Access of Portugal.

A search strategy using the following descriptors was used to identify relevant studies: Cardiac arrest AND Lucas Efficacy AND Nursing. After all these protocol requirements were met, some articles that did not meet the requirements were discarded and a reductive procedure was methodically developed.

\section{RESULTS}

It was selected for the study nine articles that follow in Table 1.

Table 1: Description of selected studies and main results of investigations

\begin{tabular}{|l|l|l|}
\hline \multicolumn{1}{|c|}{ Study (S) } & \multicolumn{1}{|c|}{ Author(s)/ Year } & \multicolumn{1}{c|}{ Main Results } \\
\hline $\begin{array}{l}\text { S1: "Automatic and } \\
\text { manual devices for } \\
\text { cardiopulmonary } \\
\text { resuscitation: A } \\
\text { review" }\end{array}$ & $\begin{array}{l}\text { Carlo Remino, Manuela } \\
\text { Baronio, Nicola Pellegrini, } \\
2018\end{array}$ & $\begin{array}{l}\text {-It was found that almost all studies and meta-analyses could not demonstrate that chest } \\
\text { compressions administered with automatic devices are more effective than those } \\
\text { administered manually. } \\
\text {-However, advances in clinical research and technology and a better understanding of } \\
\text { organisational proposals for their use are leading to a continuous improvement in the } \\
\text { effectiveness of such devices. }\end{array}$ \\
\hline $\begin{array}{l}\text { S2: "Mechanical CPR: } \\
\text { Who? When? How?" }\end{array}$ & $\begin{array}{l}\text { Kurtis Poole, Keith Couper, } \\
\text { Michael A. Smyth, Joyce } \\
\text { Yeung, Gavin D. Perkins, } \\
\text { 2018 }\end{array}$ & $\begin{array}{l}\text {-It has been verified that the provision of high quality CPR is a key modifiable factor in } \\
\text { cardiac arrest survival. } \\
\text {-It has been established that mechanical chest compression devices consistently provide } \\
\text { high quality chest compressions, but this does not lead to better patient outcomes. }\end{array}$ \\
\hline
\end{tabular}




\begin{tabular}{|c|c|c|}
\hline & & $\begin{array}{l}\text {-The use of mechanical devices in certain circumstances (e.g. ambulance or helicopter } \\
\text { transport) where high quality chest compression cannot be safely performed may be a } \\
\text { rational strategy. } \\
\text {-Further studies are needed to evaluate the routine use of mechanical devices in CPR. }\end{array}$ \\
\hline $\begin{array}{l}\text { S3: "The Efficacy of } \\
\text { LUCAS in Prehospital } \\
\text { Cardiac Arrest } \\
\text { Scenarios: A Crossover } \\
\text { Mannequin Study" }\end{array}$ & $\begin{array}{l}\text { Robert A. Gyory, Scott E. } \\
\text { Buchle, David Rodgers, } \\
\text { Jeffrey S. Lubin, } 2017\end{array}$ & $\begin{array}{l}\text {-This study provided LUCAS with more consistent chest compressions without causing } \\
\text { delays in critical resuscitation tasks such as defibrillation. } \\
\text {-In addition, LUCAS scenarios reduced the overall time for hands, which would lead to } \\
\text { maintaining adequate perfusion pressure and possibly better overall outcomes for the } \\
\text { patient. }\end{array}$ \\
\hline $\begin{array}{l}\text { S4: "Mechanical chest } \\
\text { compression devices at } \\
\text { in-hospital cardiac } \\
\text { arrest: A systematic } \\
\text { review and meta- } \\
\text { analysis" }\end{array}$ & $\begin{array}{l}\text { Keith Couper, Joyce Yeung, } \\
\text { Thomas Nicholson, Tom } \\
\text { Quinn, Ranjit Lall, Gavin D } \\
\text { Perkins, } 2016\end{array}$ & $\begin{array}{l}\text {-Study concludes that mechanical chest compression devices can improve the patient's } \\
\text { outcome when used in hospitalised cardiac arrest. } \\
\text {-However, the quality of the current evidence is very poor. } \\
\text {-There is a need for randomised studies to investigate the effect of mechanical chest } \\
\text { compression devices on survival in hospital cardiac arrest. }\end{array}$ \\
\hline $\begin{array}{l}\text { S5: "Mechanical versus } \\
\text { manual chest } \\
\text { compression for out-of- } \\
\text { hospital cardiac arrest } \\
\text { (PARAMEDIC): a } \\
\text { pragmatic, cluster } \\
\text { randomised controlled } \\
\text { trial" }\end{array}$ & $\begin{array}{l}\text { Gavin D Perkins, } \\
\text { Ranjit Lall, Tom Quinn, } \\
\text { Charles D Deakin, Matthew } \\
\text { W Cooke, } \\
\text { Jessica Horton, } \\
\text { et al., } 2015\end{array}$ & $\begin{array}{l}\text {-Study compared the group using chest compressions with the use of LUCAS and another } \\
\text { group with the use of manual compressions. } \\
\text { In this study, seven clinical adverse events were reported in the LUCAS group (three } \\
\text { patients with chest bruising, two with chest lacerations and two with blood in the mouth) } \\
\text { and } 15 \text { incidents with the device occurred during surgical use. } \\
\text {-No adverse or serious adverse events were reported in the manual group. } \\
\text { There was no evidence of an improvement in the 30-day survival rate with LUCAS } \\
\text { compared to manual compressions. } \\
\text {-Based on other recent randomised studies, the widespread introduction of mechanical } \\
\text { CPR equipment for routine use has not resulted in an improvement in survival. }\end{array}$ \\
\hline $\begin{array}{l}\text { S6: "The Study } \\
\text { Protocol for the LINC } \\
\text { (LUCAS in Cardiac } \\
\text { Arrest) Study: a study } \\
\text { comparing conventional } \\
\text { adult out-of-hospital } \\
\text { cardiopulmonary } \\
\text { resuscitation with a } \\
\text { concept with } \\
\text { mechanical chest } \\
\text { compressions and } \\
\text { simultaneous } \\
\text { defibrillation" }\end{array}$ & $\begin{array}{l}\text { Sten Rubertsson, Johan } \\
\text { Silfverstolpe, Liselott Rehn, } \\
\text { Thomas Nyman, Rob } \\
\text { Lichtveld, Rene Boomars, } \\
\text { Wendy Bruins, et al., 2013. }\end{array}$ & $\begin{array}{l}\text {-Study shows that the primary endpoint is the four-hour survival rate after triumphant } \\
\text { restoration of spontaneous circulation. } \\
\text {-The safety aspect is further assessed by postmortem examinations in } 300 \text { patients who } \\
\text { may have been injured by CPR. } \\
\text {-It was concluded that this study will contribute to the evaluation of mechanical chest } \\
\text { compression during CPR and in particular to the efficacy and safety of the LUCAS } \\
\text { device, as it will function correctly when used in conjunction with defibrillation during } \\
\text { ongoing CPR. }\end{array}$ \\
\hline $\begin{array}{l}\text { S7: "Use of the LUCAS } \\
\text { mechanical chest } \\
\text { compression device for } \\
\text { percutaneous coronary } \\
\text { intervention during } \\
\text { cardiac arrest: is it } \\
\text { really a game changer?" }\end{array}$ & $\begin{array}{l}\text { G Biondi-Zoccai, G } \\
\text { Landoni, A Zangrillo, P } \\
\text { Agostoni, G Sangiorgi, M G } \\
\text { Modena, } 2011\end{array}$ & $\begin{array}{l}\text {-It has been verified that cardiopulmonary support, including chest compression, is a } \\
\text { major support in the treatment of cardiac arrest. } \\
\text {-However, chest compression by traditional means can be challenging, especially in } \\
\text { patients requiring urgent invasive procedures such as percutaneous coronary intervention } \\
\text { for cardiac arrest due to acute myocardial infarction. } \\
\text {-The LUCAS mechanical chest compression device provides external and automated } \\
\text { chest compression, enabling even complex invasive procedures without interrupting } \\
\text { cardiopulmonary support. } \\
\text {-However, no randomized study has yet demonstrated its benefit compared to standard } \\
\text { manual chest compression, and to date only observational studies and consensus opinions } \\
\text { support its clinical use. }\end{array}$ \\
\hline
\end{tabular}

\section{DISCUSSION}

The survival rate without any neurological consequences of cardiac arrest is determined not only by early detection but also by high-quality cardiopulmonary resuscitation. Since the effectiveness of manual CPR is usually impaired by rescuers' fatigue, devices have been developed to improve it through equipment or ergonomic solutions. However, it is assumed that some devices completely replace manual resuscitation, either by unleashing its effects or by generating hemodynamic 
effects with completely different working principles. This article provides an overview of such devices, both manual and automatic. They are mainly classified by method of actuation, applied force, working space and positioning time (Remino et al., 2018). These facts are consistent with all studies, especially with the S2, S5 and S6 studies.

The hemodynamic performance of the LUCAS compression-decompression system is better than that of manual CPR, according to the results of studies S3, S4, S6 and S7. The data from this study confirm data from the literature on the same subject. According to current knowledge, automated systems for external cardiac massage provide hemodynamic benefits thanks to the quality of the massage and ensure better cerebral and myocardial perfusion over a longer period of time. However, although the benefit to physiological data has been demonstrated, no human studies have clearly shown that automated systems improve survival, neurological prognosis or ROSC percentage, as the S2 study shows (Gates et al., 2012). Prolonged cardiac massage is still the only indication for the use of these devices. Achieving optimal hemodynamic parameters is also essential to achieve the best possible tissue perfusion in the event of transplantation in cardiac arrest or the decision to initiate circulatory support during chronography (Fox et al., 2013). Automatic devices do not fatigue at all and can continue to massage during defibrillation or other necessary surgery (Libungan et al., 2014). In addition, if a strict stretcher is used during the transport of the patient from the accident site to the ambulance, the massage can continue uninterrupted, as described in the S2 and S3 studies. The LUCAS device does not fatigue or interrupt the compressions, and it provides uniform depth and rate of chest compressions. Of course, it gives a provider the freedom to perform other treatments and it provides improved patient access. The patient can be safely moved and transported while undergoing CPR. Defibrillation can be performed while the device is in operation.

In the literature there are some references to the poor quality of chest compression (Kampmeier et al., 2014). Consequently, chest compression is as crucial as alerting the emergency services or early defibrillation in the survival chain. According to the guidelines, chest compressions must be performed continuously in order to improve the outcome, according to the reviewers of all studies. However, the effectiveness of manual chest compression decreases over time with provider fatigue (which appears to be trapped by the minutes of the start of the procedure) and is compromised during transport, exposing patients to unexpected interruptions and a deterioration in the quality of the massage in terms of strength and rhythm (Walcott et al., 2007). These facts are confirmed by studies S2 and E7, which found that the quality of chest compressions is impaired during transport, e.g. in an ambulance or helicopter. It has been reported that the effectiveness of manual chest compression decreases by $20 \%$ per minute (Ock et al., 2011, Blomberg et al., 2011). Mechanical chest compression overcomes this problem of operator fatigue by ensuring continuous effectiveness in both qualitative and quantitative terms, as it mentions S5 and S1.

Complications induced by manual CPR have been reported in the literature, including cardiac rupture, aortic and vena cava injuries, esophageal rupture, rupture of solid organs and multiple rib fractures. However, there are few robust methodological studies that compare the actual complication rates of CPR methods. Deras et al (2014) concluded that the injuries seen with LUCAS appear to be of the same variety and incidence as those seen with manual CPR, as described in study S5. Regardless of the type of CPR performed, it is critical that the compressions are applied in the correct anatomical location and that their application requires consistent and careful monitoring (Bonnemeier et al., 2008; Smekal et al., 2009). Even if the compressions are applied correctly, the complication potential of manual and automated CPR is real, as developed in S2, S3, S4, S6 and S7. However, it should not be forgotten that the last complication has already occurred in these patients, and we have a duty to provide all patients with the care that offers them the highest chance of survival. This risk-benefit ratio is of crucial importance to readers (Steen et al. 2002; Matsuura et al., 2008; Yannopoulos et al., 2014). The results of the studies are mixed, with four of them stating that LUCAS is fully effective, particularly in fatigue and transport, but two of them do not recognize its full effectiveness. One of the studies mentions that the fact that compression by the automatic device is effective does not necessarily reflect a better result. The vast majority of studies recognize the need for further studies (particularly S2, S4 and S7) to make more convincing decisions.

\section{CONCLUSION}

With regards the results of the studies analysed, it should be noted that there are data in these studies that show that LUCAS is very effective in cardiac compressions either before or during hospitalisation, in the patient's results, and that the device is safe for the patient and does not cause undue serious injury to the patient. On the other hand, there are studies that point out as disadvantages of the use of LUCAS.

Automatic devices deliver compressions at a more consistent rate and depth than manual compressions. However, AHA does not recommend the routine use of automatic devices, as there is no evidence that they achieve a better result than 
manual massage. Automated devices must be applied to the patient and this requires time, especially if personnel are not familiar with the device and not properly trained. There is a knowledge curve to overcome and the performance of a resuscitation team habitually improves over time with practice and regular training. However, as there is not enough data on real patients, this area is obviously ripe for future work.

A conclusion section is not required. Although a conclusion may review the main points of the paper, do not replicate the abstract as the conclusion. A conclusion might elaborate on the importance of the work or suggest applications and extensions.

\section{REFERENCES}

1. Agostoni, P., Cornelis, K., Vermeersch, P. (2008). Successful percutaneous treatment of an intraprocedural left main stent thrombosis with the support of an automatic mechanical chest compression device. Int J Cardiol. 124, 19-21.

2. American Heart Association (2010). Destaques das Diretrizes da American Heart Association 2010 para RCP e ACE (versão em Português).

3. Aufderheide, T., Frascone, R., Wayne, M., et al. (2011). Standard cardiopulmonary resuscitation versus active compression-decompression cardiopulmonary resuscitation with augmentation of negative intrathoracic pressure for out-of-hospital cardiac arrest: a randomised trial. Lancet, 377, 301-11.

4. Benefield, L. (2003). Implementing evidence-based practice in home care. Home Healthcare Nurse, 21, 804-811.

5. Biondi-Zoccai, G., Landoni, G., Zangrillo, A., Agostoni, P., Sangiorgi, G., Modena, M., (2011). Use of the LUCAS mechanical chest compression device for percutaneous coronary intervention during cardiac arrest: is it really a game changer?. HSR Proc Intensive Care Cardiovasc Anesth, 3(3), 203-205.

6. Blomberg, H., Gedeborg, R., Berglund, L., et al. (2011). Poor chest compression quality with manual compressions in a simulated cardiopulmonary resuscitation: a randomized, cross-over mannequin study. Resuscitation, 82:13327.

7. Bonnemeier, H., Gerling, I., Barantke, M., et al. (2008). Necropsy findings of non survivors of CPR after mechanical and conventional chest compression. ERC Congress.

8. Brooks, S., Bigham, B., Morrison, L. (2014). Mechanical versus manual chest compressions for cardiac arrest. Cochrane Database Syst Rev.

9. Couper, K., Yeung, J., Nicholson, T., Quinn, T., Lall, R., Perkins, G. (2016). Mechanical chest compression devices at in-hospital cardiac arrest: A systematic review and meta-analysis. Resuscitation, 103, 24-31. doi: 10.1016/j.resuscitation.2016.03.004.

10. Couper, K., Smyth, M., Perkins, G. (2015). Mechanical devices for chest compression: to use or not to use? Curr Opin Crit Care, 21, 188-194.

11. Deras, P., Manzanera, J., Millet, I., Charbit, J., Capdevila, X. (2014). Fatal pancreatic injury due to trauma after successful cardiopulmonary resuscitation with automatic mechanical chest compression. Anesthesiology, 120, 1038-41.

12. Fox, J., Fiechter, R., Gerstl, P., Url, A., Wagner, H., et al. (2013). Mechanical versus manual chest compression CPR under ground ambulance transport conditions. Acute Card Care, 15, 1-6.

13. Gates, S., Smith, J., Ong, G., Brace, S., Perkins, G. (2012). Effectiveness of the LUCAS device for mechanical chest compression after cardiac arrest: systematic review of experimental, observational and animal studies. Heart., 98, 908-913.

14. Gyory, R., Buchle, S., Rodgers, D., Lubin, J. (2017). The Efficacy of LUCAS in Prehospital Cardiac Arrest Scenarios: A Crossover Mannequin Study. West J Emerg Med., 18(3), 437-445, doi: 10.5811/westjem.2017.1.32575

15. Hewitt, C., Torgerson, D., Miles, J. (2006). Is there another way to take account of noncompliance in randomized controlled trials? Can Med Assoc J., 175, 347.

16. Idris, A., Guffey, D., Pepe, P., et al. (2015). Chest compression rates and survival following out-of-hospital cardiac arrest. Crit Care Med, 43, 840-848.

17. Kampmeier, T., Lukas, R., Steffler, C., Sauerland, C., Weber, T., et al. (2014). Chest compression depth after change in CPR guidelines--improved but not sufficient. Resuscitation, 85, 503-508. 
18. Kleinman, M., Brennan, E., Goldberger, Z., Partdult (2015). Basic life support and cardiopulmonary resuscitation quality: 2015. American heart association guidelines update for cardiopulmonary resuscitation and emergency cardiovascular care. Circulation, 132, 414-135.

19. Libungan, B., Dworeck, C., Omerovic, E. (2014). Successful percutaneous coronary intervention during cardiac arrest with use of an automated chest compression device: a case report. Ther Clin Risk Manag., 10, 255-257.

20. Matsuura, T., McKnite, S., Metzger, A., Yannopoulos, D., Aufderheide, T., Lurie, K. (2008). An impedance threshold device combined with an automated active compression decompression CPR device (LUCAS) improves the chances for survival in pigs in cardiac arrest. Circulation, 118, 1449-50.

21. Mendes, A., Fracolli, L. (2008). Revisão sistemática de literatura e metassíntese qualitativa: considerações sobre sua aplicação na pesquisa em enfermagem. Texto Contexto Enfermagem, 17(4), 771-778.

22. Neumar, R., Otto, C., Link, M. (2010). Part8: Adult advanced cardiovascular life support: 2010 American heart association guidelines for cardiopulmonary resuscitation and emergency cardiovascular care. Circulation, 122, 729167.

23. Nishiyama,C., Brown, S., May, S., et al. (2014). Apples to apples or apples to oranges? International variation in reporting of process and outcome of care for out-of-hospital cardiac arrest Resuscitation, 85, 1599-1609.

24. Ock, S., Kim, Y., Chung, J., Kim, S. (2011). Influence of physical fitness on the performance of 5-minute continuous chest compression. Eur J Emerg Med., 18, 251-256.

25. Perkins, G., Cooke, M. (2012). Variability in cardiac arrest survival: the NHS Ambulance Service Quality Indicators Emerg Med J, 29, 3-5.

26. Perkins, G., Lall, R., Quinn, T., Phil, M., Deakin, C., Cooke, M., Horton, J., et al. (2015). Mechanical versus manual chest compression for out-of-hospital cardiac arrest (Paramedic): a pragmatic, cluster randomised controlled trial, The Lancet., doi:https://doi.org/10.1016/S0140-6736(14)61886-9.

27. Poole, K., Couper, K., Smyth, M., Yeung, J., Perkins, G. (2018). Mechanical CPR: Who? When? How?. Critical Care. BMC, research in progress, 22, 140.

28. Rubertsson, S., Silfverstolpe, J., Rehn, L., Nyman, T., Lichtveld, R., Boomars, R., et al. (2013). The Study Protocol for the LINC (LUCAS in Cardiac Arrest) Study: a study comparing conventional adult out-of-hospital cardiopulmonary resuscitation with a concept with mechanical chest compressions and simultaneous defibrillation. Scand J Trauma Resusc Emerg Med., 25, 21-5. doi: 10.1186/1757-7241-21-5.

29. Remino, C., Baronio, M., Pellegrini, N. (2018). Automatic and manual devices for cardiopulmonary resuscitation: A review Research Article, Advances in Mechanical Engineering, https://doi.org/10.1177/1687814017748749.

30. Riley, R., Higgins, J., Deeks, J. (2011). Interpretation of random effects meta-analyses BMJ. Clin Res Ed., 342, 549.

31. Santos, C., Pimenta, Nobre, C. (2007). A estratégia pico para a construção da pergunta de pesquisa e busca de evidências. Revista Latino-Americana Enfermagem, 15(3), 508-511.

32. Smekal, D., Johansson, J., Huzevka, T., et al. (200). No difference in autopsy detected injuries in cardiac arrest patients treated with manual chest compressions compared with mechanical compressions with the LUCAS devicea pilot study. Resuscitation, 80, 1104-7

33. Stiell, I., Brown, S., Christenson, J., et al. (2012). What is the role of chest compression depth during out-of-hospital cardiac arrest resuscitation? Crit Care Med, 40, 1192-1198.

34. Steen, S., Liao, Q., Pierre, L., et al. (2002). Evaluation of LUCAS, a new device for automatic mechanical chest compression and active decompression for cardiopulmonary resuscitation. Resuscitation.

35. Walcott, P., Melnick, S., Banville, I., et al. (2007). Pauses for defibrillation not necessary during mechanical chest compressions during pre-hospital cardiac arrest. Circulation, 116, 1811.

36. Wagner, H., Terkelsen, C., Friberg, H., et al. (2010). Cardiac arrest in the catheterisation laboratory: a 5-year experience of using mechanical chest compressions to facilitate PCI during prolonged resuscitation efforts. Resuscitation, 81, 383-7.

37. Wik, L., Kramer-Johansen, J., Myklebust, H., et al. (2005). Quality of cardiopulmonary resuscitation during outof-hospital cardiac arrest. JAMA, 293, 299-304.

38. Yannopoulos, D., Matsuura, T., Wayne, M., Mahoney, B., Frascone, R., Fahey, B., Lick, C., Waytz, J., Segal, N. (2014). Evaluation of the hemodynamic synergy between an impedance threshold device and the LUCAS 2 automated CPR device in a pig model of cardiac arrest. Prehosp Emerg Care, 18, 131. 